\title{
Two-fund separation in dynamic general equilibrium
}

\author{
KARL SCHMEDDERS \\ Kellogg School of Management, Northwestern University
}

This paper examines the two-fund separation paradigm in the context of an infinite-horizon general equilibrium model with dynamically complete markets and heterogeneous consumers with time- and state-separable utility functions. With the exception of the dynamic structure, we maintain the assumptions of the classical static models that exhibit two-fund separation with a riskless security. Agents have equi-cautious HARA utility functions. In addition to a security with state-independent payoffs, agents can trade a collection of assets with dividends following a time-homogeneous Markov process. We make no further assumptions about the distribution of asset dividends, returns, or prices. If the riskless security in the economy is a consol then agents' portfolios exhibit two-fund separation. However, if agents can trade only a one-period bond, this result no longer holds. The underlying intuition is that general equilibrium restrictions lead to interest rate fluctuations that destroy the optimality of two-fund separation in economies with a one-period bond and result in different equilibrium portfolios.

KeYwords. Portfolio separation, dynamically complete markets, consol, oneperiod bond, interest rate fluctuation, reinvestment risk.

JEL CLASSIFICATION. D53, G11, G12.

\section{INTRODUCTION}

The two-fund separation theorem, which is among the most remarkable results of classical finance theory, states that investors who must allocate their wealth between a number of risky assets and a riskless security should all hold the same mutual fund of risky assets. An investor's risk aversion affects only the proportions of wealth that he invests in the risky mutual fund and the riskless security. The allocation of wealth across the different risky assets does not depend on the investor's preferences.

Cass and Stiglitz (1970) and Merton (1973) are perhaps the most prominent works on this fundamental result. Cass and Stiglitz (1970) derive necessary and sufficient conditions on investors' utility functions for the optimal portfolio in investors' static asset

Karl Schmedders: $\mathrm{k}$-schmedders@northwestern.edu

I thank Ken Judd, Felix Kubler, Christoph Kuzmics, and Costis Skiadas for helpful discussions and audiences at SUNY at Stony Brook, the 2004 NBER-NSF general equilibrium conference at UC Davis, the University of Frankfurt, and the 'Weihnachtstreffen' in Bielefeld for comments. I am indebted to Michael Magill and Martine Quinzii for making their unpublished book chapters on 'Elements of Differential Topology' available to me. I am grateful to the Co-Editor Ed Green and two anonymous referees for very useful suggestions on an earlier draft.

Copyright (c) 2007 Karl Schmedders. Licensed under the Creative Commons Attribution-NonCommercial License 2.5. Available at http: / / econtheory . org. 
demand problems to satisfy the separation property. They use the phrase "monetary separation" for the notion of portfolio separation that most people now have in mind when they talk about two-fund separation, specifically for the separation of investors' portfolios into the riskless asset and a common mutual fund of risky assets. For examples, see Canner et al. (1997) and Elton and Gruber (2000). Merton (1973) establishes two-fund monetary separation for an intertemporal capital asset pricing model in a continuous-time setting without assumptions on utility functions but under the conditions that the returns of the risky assets are log-normally distributed and that the interest rate is constant through time. Although these two seminal works along with many other papers on the subject have established the two-fund separation paradigm at the heart of the foundations of modern finance theory, the paradigm has not been examined in the context of the celebrated Lucas asset pricing model (Lucas 1978). This paper aims to fill this gap in the literature.

We prove that in a Lucas-style discrete-time infinite-horizon general equilibrium model with heterogeneous agents, two-fund monetary separation holds only if a consol, a perpetual bond with safe coupon payments and no maturity date, is available for trade on financial markets. Two-fund separation typically fails if only risky assets and a one-period bond (cash) can be traded on financial markets. In the model, markets are dynamically complete and utility functions are time- and state-separable. All asset dividends or payoffs follow a time-homogeneous Markov process. Efficient equilibria in this model have time-homogeneous consumption and asset price processes. After one round of initial trading, portfolios are constant over time. We emphasize that we do not impose this buy-and-hold nature of agents' portfolios ex ante, but that this feature is a result of equilibrium efficiency in the general equilibrium model (Judd et al. 2003). We maintain the classical assumptions on utility functions (Cass and Stiglitz 1970). All agents have HARA utilities with linear absolute risk tolerances having identical slopes. We assume that in addition to stocks with Markovian dividend processes there is also a security with state-independent payoffs (consol or cash). The general equilibrium nature of our model prohibits us from making any further assumptions about the distribution of asset returns or prices. These quantities, along with interest rates, are determined in equilibrium.

The underlying intuition for our results is that general equilibrium restrictions create interest rate fluctuation. This fluctuation affects agents holding a consol differently than agents holding a one-period bond. Portfolios are constant over time in the dynamic model equilibrium. When a consol is present, an agent establishes a desired position at time zero and then keeps this consol holding forever. Changes in the price (interest rate) of the consol do not affect the agent since she does not trade the consol. In an economy without a consol but with a one-period bond, equilibrium portfolios are also constant over time. Now, however, an agent must reestablish the constant bond position in every period. In such an environment the agent faces reinvestment risk due to bond price (interest rate) fluctuation in equilibrium. This fluctuation destroys the optimality of two-fund separation and leads to a different equilibrium portfolio.

The first two-fund separation results were obtained by Tobin (1958) and Markowitz (1959), who analyze portfolio demand in the mean-variance framework. Subsequent 
work on two-fund separation revealed that either assumptions on utility functions or on asset return distributions (or both) are necessary to establish further results. Cass and Stiglitz (1970) derive necessary and sufficient conditions on investors' utility functions that ensure two-fund separation in investors' static asset demand problems. Ross (1978) presents conditions on asset return distributions under which two-fund separation holds for static demand problems. Russell (1980) presents a unified approach of Cass and Stiglitz and Ross. Ingersoll (1987) provides a detailed overview of various separation results, and highlights the distinction between restrictions on utility functions and restrictions on asset return distributions. Rubinstein (1974) shows that if all investors have equi-cautious HARA utility, then the two-fund monetary separation theorem holds in an equilibrium model. Essentially he extends the Cass-Stiglitz result to equilibrium analysis. (We use the same assumption of equi-cautious HARA utilities in a dynamic general equilibrium model.) Gollier (2001) also states the separation result of Cass and Stiglitz in the context of a static equilibrium model. We cannot possibly do justice to the huge literature on portfolio separation and mutual fund theorems in static models and, therefore, just refer to textbook overviews such as Ingersoll (1987) or Huang and Litzenberger (1988), and to the summary in Ross (1978).

The standard reference for two-fund separation in dynamic economies is Merton (1973), even though some of the results are already present in Merton (1971). Merton (1973) shows for his continuous-time capital asset pricing model that two-fund monetary separation holds independently of preferences, wealth distribution, and time horizon, if returns of risky assets are log-normally distributed and the investment opportunity set is constant. The latter assumption requires, among other conditions, the interest rate of the riskless asset to be constant over time. Merton also shows that two-fund separation no longer holds as soon as the (instantaneously riskless) interest rate changes stochastically over time. He establishes a "three fund" theorem, but both the composition of the fund of risky assets and agents' holdings of the three funds change continuously over time. For a further generalization of the three-fund theorem to an $m$-fund theorem, see Merton (1990). We relate our results in this paper to Merton's theorems in our discussion of a detailed example in Section 3.

The paper is organized as follows. In Section 2 we describe the general equilibrium model and characterize efficient equilibria. Section 3 presents an illustrative example exposing the basic intuition underlying our results. In Section 4 we state some helpful equilibrium properties. Section 5 develops the two-fund separation theory for our dynamic model, proving the generalization of the classical static result when a consol is available for trade and showing that two-fund separation fails generically when there is only a one-period bond. Section 6 points to the relevance of our results for the asset allocation puzzle. The Appendix contains all technical proofs.

\section{THE ASSET MARKET ECONOMY}

The purpose of this section is to introduce the economic framework for all the analysis in this paper. We first describe the general equilibrium model with dynamically complete markets. Next we explain how we can easily characterize efficient equilibria in 
the model. And finally we review the notion of two-fund monetary separation for the general equilibrium model.

\subsection{General equilibrium model}

We examine a standard Lucas asset pricing model (Lucas 1978) with heterogeneous agents and dynamically complete asset markets. Time is indexed by $t \in \mathbb{N}_{0} \equiv\{0,1,2, \ldots\}$. A time-homogeneous recurrent Markov process of exogenous states $\left(y_{t}\right)_{t \in \mathbb{N}_{0}}$ takes values in a discrete set $\mathscr{Y}=\{1,2, \ldots, S\}, S \geq 2$. The Markov transition matrix is denoted by $\Pi$. A date-event $\sigma_{t}$ is the history of shocks up to time $t$, i.e. $\sigma_{t}=\left(y_{0} y_{1} \ldots y_{t}\right)$. Let $\Sigma_{t}$ denote the possible histories $\sigma_{t}$ up to time $t$ and let $\Sigma=\cup_{t} \Sigma_{t}$ denote all possible histories of exogenous states. We denote the predecessor of a date-event $\sigma \in \Sigma$ by $\sigma^{*}$. The starting node $\sigma_{0}=y_{0}$ has a predecessor $\sigma_{0}^{*}=\sigma_{-1}$.

There is a finite number of types $\mathscr{H}=\{1,2, \ldots, H\}$ of infinitely-lived agents. There is a single perishable consumption good, which is produced by firms. The agents have no individual endowment of the consumption good. The firms distribute their output each period to its owners through dividends. Investors trade shares of the firms and other securities in order to transfer wealth across time and states. There are $J=S$ assets traded on financial markets. An asset is characterized by its state-dependent dividends or payoffs. We denote asset $j$ 's dividend or payoff by $d^{j}: \mathscr{Y} \rightarrow \mathbb{R}_{+}, j=1, \ldots, S$, which solely depends on the current state $y \in \mathscr{Y}$. Each security is either an infinitely-lived (longlived) asset or a single-period asset. There are $J^{l} \geq 1$ long-lived assets in the economy. The remaining $S-J^{l}$ securities are short-lived assets that are issued in each period. A short-lived asset $j$ issued in period $t$ pays $d^{j}(y)$ in period $t+1$ if state $y$ occurs and then expires. For ease of exposition we collect the infinitely lived assets in a set $L \equiv\left\{1, \ldots, J^{l}\right\}$ and the one-period assets in a set $O \equiv\left\{J^{l}+1, \ldots, S\right\}$.

We denote the portfolio of agent $h$ at date-event $\sigma \in \sum$ by $\theta^{h}(\sigma) \equiv\left(\theta^{h L}(\sigma), \theta^{h O}(\sigma)\right)=$ $\left(\theta^{h 1}(\sigma), \ldots, \theta^{h S}(\sigma)\right) \in \mathbb{R}^{S}$. His initial endowment of asset $j$ prior to time 0 is denoted by $\theta_{-1}^{h j}, j \in L$. Each agent has zero initial endowment of the short-lived assets and so these assets are in zero net supply. The infinitely-lived assets that represent firm dividends are in unit net supply. Other financial assets, such as a consol, are in zero net supply. We write $\theta_{-1}^{L} \equiv\left(\theta_{-1}^{h L}\right)_{h \in \mathscr{H}}$. The aggregate endowment of the economy in state $y$ is $e(y)=$ $\sum_{j \in L}\left(\sum_{h \in \mathscr{H}} \theta_{-1}^{h j}\right) d^{j}(y)$. Agent $h$ 's initial endowment of dividends before time 0 is given by $\omega^{h}(y)=\sum_{j \in L} \theta_{-1}^{h j} d^{j}(y)>0$. To avoid unnecessary complications we assume that all agents have nonnegative initial holdings of each asset and a positive initial holding of at least one asset.

Let $q(\sigma) \equiv\left(q^{1}(\sigma), \ldots, q^{S}(\sigma)\right)$ be the prices of all assets at date-event $\sigma$ after dividends or coupon payoffs have been paid. At each date-event $\sigma=\left(\sigma^{*} y\right)$ agent $h$ faces the budget constraint

$$
c^{h}(\sigma)=\sum_{j \in L} \theta^{h j}\left(\sigma^{*}\right)\left(q^{j}(\sigma)+d^{j}(y)\right)+\sum_{j \in O} \theta^{h j}\left(\sigma^{*}\right) d^{j}(y)-\sum_{j=1}^{S} \theta^{h j}(\sigma) q^{j}(\sigma) .
$$


Each agent $h$ has a time-separable utility function

$$
U_{h}(c)=E\left\{\sum_{t=0}^{\infty} \beta^{t} u_{h}\left(c_{t}\right)\right\},
$$

where $c=\left(c_{0}, c_{1}, c_{2}, \ldots\right)$ is a consumption process. All agents have the same discount factor $\beta \in(0,1)$. We assume that the Bernoulli functions $u_{h}: X \rightarrow \mathbb{R}$ are strictly monotone, twice differentiable, and strictly concave on some interval $X \subset \mathbb{R}$. Below we discuss conditions that ensure equilibrium consumption at every date-event to always lie in the interior of an appropriately chosen consumption set $X$.

Let the matrix

$$
d=\left(d^{1}, \ldots, d^{S}\right)=\left(\begin{array}{ccc}
d^{1}(1) & \cdots & d^{S}(1) \\
\vdots & \ddots & \vdots \\
d^{1}(S) & \cdots & d^{S}(S)
\end{array}\right)
$$

represent security dividends or payoffs. The vector of utility functions is $U=\left(U_{1}, \ldots, U_{H}\right)$. We denote the primitives of the economy by the expression $\mathscr{E}=\left(d, X, \beta, U ; \theta_{-1}^{L}, \Pi\right)$.

We define a standard notion of financial market equilibrium.

DEFINITION 1. A financial market equilibrium for an economy $\mathscr{E}$ is a process of portfolio holdings $\left\{\left(\bar{\theta}^{1}(\sigma), \ldots, \bar{\theta}^{H}(\sigma)\right)\right\}$ and asset prices $\left\{\left(\bar{q}^{1}(\sigma), \ldots, \bar{q}^{S}(\sigma)\right)\right\}$ for all $\sigma \in \sum$ satisfying the following conditions.

1. $\sum_{h=1}^{H} \bar{\theta}^{h}(\sigma)=\sum_{h=1}^{H} \theta_{-1}^{h}$ for all $\sigma \in \Sigma$.

2. For each agent $h \in \mathscr{H}$,

$$
\begin{aligned}
& \left(\bar{\theta}^{h}(\sigma)\right)_{\sigma \in \Sigma} \in \underset{\theta}{\arg \max } U_{h}(c) \quad \text { s.t. } \\
& \qquad c^{h}(\sigma)=\sum_{j \in L} \bar{\theta}^{h j}\left(\sigma^{*}\right)\left(\bar{q}^{j}(\sigma)+d^{j}(y)\right)+\sum_{j \in O} \bar{\theta}^{h j}\left(\sigma^{*}\right) d^{j}(y)-\sum_{j=1}^{S} \bar{\theta}^{h j}(\sigma) \bar{q}^{j}(\sigma) \\
& \quad \text { and } \sup _{\sigma \in \Sigma}\left|\sum_{j=1}^{S} \bar{\theta}^{h j}(\sigma) \bar{q}^{j}(\sigma)\right|<\infty .
\end{aligned}
$$

\subsection{Equilibrium in dynamically complete markets}

Judd et al. (2003) characterize efficient financial market equilibria in our model through a simple system of equations. (See also the comments by Bossaerts and Zame 2006 and the reply by Judd et al. 2006b.) Here we summarize their results and defer a more technical discussion of the underlying assumptions until Section 4.

Two results of Judd et al. (2003) greatly simplify the equilibrium analysis. First, efficient equilibria exhibit time-homogeneous consumption processes and asset prices. That is, consumption allocations and asset prices in date-event $\sigma=\left(\sigma^{*} y\right)$ depend only 
on the last shock $y$. Second, after one round of initial trading in period 0 , each agent's portfolio is constant across states and time. So equilibrium portfolios do not even depend on the last shock $y$. These results imply that we do not need to express equilibrium values as functions of the date-event $\sigma$ or through policy or value functions on some large state space. Instead we can index consumption and asset prices with the current exogenous shock $y$ through a subscript. For example, $c_{y}^{h}$ denotes the consumption of agent $h$ in state $y$.

The simple structure of efficient equilibria means that computing an equilibrium reduces to finding finitely many numbers. We first can compute equilibrium consumption allocations using the Negishi approach (Negishi 1960) of Judd et al. (2003). For this purpose we define $p_{y}=u_{1}^{\prime}\left(c_{y}^{1}\right)$ to be the price of consumption in state $y$ and $p=\left(p_{y}\right)_{y \in \mathscr{Y}} \in$ $\mathbb{R}_{++}^{S}$ to be the (column) vector of prices. We denote the $S \times S$ identity matrix by $I_{S}$, Negishi weights by $\lambda^{h}, h=2, \ldots, H$, and use $\otimes$ to denote element-wise multiplication of vectors. If the economy starts in the state $y_{0} \in \mathscr{Y}$ at time $t=0$, then the Negishi weights and consumption vectors must satisfy the following equations.

$$
\begin{aligned}
u_{1}^{\prime}\left(c_{y}^{1}\right)-\lambda^{h} u_{h}^{\prime}\left(c_{y}^{h}\right) & =0, & & h=2, \ldots, H, y \in \mathscr{Y}, \\
\left(\left[I_{S}-\beta \Pi\right]^{-1}\left(p \otimes\left(c^{h}-\omega^{h}\right)\right)\right)_{y_{0}} & =0, & & h=2, \ldots, H, \\
\sum_{h=1}^{H} c_{y}^{h}-\sum_{h=1}^{H} \omega_{y}^{h} & =0, & & y \in \mathscr{Y} .
\end{aligned}
$$

Equations (1) require that marginal utility vectors are collinear. Equations (2) are the (infinite-horizon) budget equations for agents $h=2,3, \ldots, H$, given that the economy starts in state $y_{0}$. Walras' Law allows us to omit the budget equation for the first agent in the presence of the market-clearing conditions (3). The equations (1)-(3) constitute a nonlinear system with $H S+(H-1)$ unknowns and equations. There are $H S$ unknown state-contingent consumption levels $c_{y}^{h}, h \in \mathscr{H}, y \in \mathscr{Y}$, and $H-1$ Negishi weights $\lambda^{h}$, $h=2,3, \ldots, H$. We can easily solve such a system of equations on a personal computer using Newton's method.

Once we know the consumption levels and thus the state price vector $p$ we determine asset prices from the Euler equations. The price vector $q^{j}=\left(q_{y}^{j}\right)_{y \in \mathscr{Y}}$ of a long-lived asset $j$ is given by the linear expressions

$$
q^{j} \otimes p=\left[I_{S}-\beta \Pi\right]^{-1} \beta \Pi\left(p \otimes d^{j}\right) .
$$

The price of a short-lived asset $j$ in state $y$ is

$$
q_{y}^{j}=\frac{\beta \Pi_{y} \cdot\left(p \otimes d^{j}\right)}{p_{y}},
$$

where $\Pi_{y}$. denotes row $y$ of the transition matrix $\Pi$.

In the last step we can compute agents' portfolios from their budget equations. After one initial round of trading at time 0 , all agents hold a state-independent portfolio vector $\Theta^{h} \equiv \theta_{y}^{h}$ for all $y \in \mathscr{Y}$. Define the matrix $D=\left(d^{1}, \ldots, d^{J^{l}}, d^{J^{l}+1}-q^{J^{l}+1}, \ldots, d^{S}-q^{S}\right)$. The 
portfolio of agent $h, h \in \mathscr{H}$, is now the solution to the linear system of budget equations across all states $y \in \mathscr{Y}$,

$$
c^{h}=D \Theta^{h} .
$$

In summary, the consumption allocations, asset prices, and portfolio holdings in every efficient financial market equilibrium solve the system of equations (1)-(6) (and vice versa). All our analysis in this paper is based on this characterization of equilibria. In Section 3 we solve these equations numerically to compute an equilibrium for an illustrative example. In Sections 4 and 5 we use the equations to prove general results for our model.

\subsection{Two-fund separation}

Classical two-fund monetary separation (see, for example, Cass and Stiglitz 1970, Merton 1973, Ingersoll 1987, Huang and Litzenberger 1988) states that investors who must allocate their wealth between a number of risky assets and a riskless security should all hold the same mutual fund of risky assets. An investor's risk aversion affects only the proportions of wealth that (s)he invests in the risky mutual fund and the riskless security. The allocation of wealth across the different risky assets does not depend on the investor's preferences. In the context of our general equilibrium model with several heterogeneous agents this property states that the proportions of wealth invested in any two risky assets are the same for all agents in the economy.

DEFINITION 2. Consider an economy $\mathscr{E}$ with an asset that has a riskless payoff vector, $d_{y}^{S}=1$ for all $y \in \mathscr{Y}$. The remaining $S-1$ assets are risky and in unit net supply. We say that portfolios exhibit two-fund monetary separation if

$$
\frac{q_{y}^{j} \Theta^{h j}}{q_{y}^{k} \Theta^{h k}}=\frac{q_{y}^{j} \Theta^{h^{\prime} j}}{q_{y}^{k} \Theta^{h^{\prime} k}}
$$

for all assets $j, k \neq S$ and all agents $h, h^{\prime} \in \mathscr{H}$ in all states $y \in \mathscr{Y}$.

All risky assets are in unit net supply and so market clearing and the requirement from the definition immediately imply that all agents' portfolios exhibit two-fund separation if and only if $\Theta^{h j}=\Theta^{h k}$ for all assets $j, k \neq S$ and all agents $h \in \mathscr{H}$. That is, in equilibrium each agent must have a constant share of every risky asset in the economy. The ratio of wealth invested in any two risky assets $j, k \neq S$ equals the ratio $q_{y}^{j} / q_{y}^{k}$ of their prices and thus depends on the state $y \in \mathscr{Y}$.

\section{ILLUSTRATIVE EXAMPLE}

The purpose of this section is to illustrate the basic theme of the paper in the context of an example. Two-fund separation holds in an economy with a consol but it typically fails in an economy with a one-period bond (under some standard assumptions on utilities).

The following simple example has essentially the minimal structure to capture the main issues. Each period there are $S=3$ states, which are all equally likely. That is, all 
elements of the Markov transition matrix are $\frac{1}{3}$. There are two stocks with the following dividend vectors.

$$
\begin{aligned}
& d^{1}=(1.1,1.0,0.9)^{\top} \\
& d^{2}=(1.4,0.8,0.8)^{\top} .
\end{aligned}
$$

The aggregate endowment in our economy is then $e=d^{1}+d^{2}=(2.5,1.8,1.7)^{\top}$. There are $H=2$ agents who have CARA (Bernoulli) utility functions

$$
u_{h}(c)=-\frac{1}{a^{h}} e^{-a^{h} c}
$$

with coefficients of absolute risk-aversion $a^{1}=1$ and $a^{2}=4$, respectively. The agents' discount factor is $\beta=0.95$. Initially, the agents both hold half of each stock. That is, their initial holdings are $\theta_{-1}^{h j}=\frac{1}{2}$ for $h=1,2, j=1,2$. The economy starts in state $y_{0}=1$.

Equations (1)-(3) determine the equilibrium consumption allocation in this economy. We can easily solve this system of 7 nonlinear equations in 7 unknowns with Newton's method. Denoting the vector $(1,1,1)^{\top}$ by $1_{3}$ we obtain the following consumption vectors (rounded to three digits).

$$
\begin{aligned}
& c^{1}=(1.421,0.861,0.781)^{\top}=0.8 \cdot\left(d^{1}+d^{2}\right)-0.579 \cdot 1_{3} \\
& c^{2}=(1.079,0.939,0.919)^{\top}=0.2 \cdot\left(d^{1}+d^{2}\right)+0.579 \cdot 1_{3} .
\end{aligned}
$$

Consumption allocations are determined by linear sharing rules. This feature of the consumption allocations is the key property underlying two-fund separation in an economy with a consol. Whenever agents' consumption follows a linear sharing rule, asset portfolios exhibit two-fund separation in the presence of a consol.

Next we can determine the stock prices. We know the consumption allocations of the first agent and thus the vector of state prices $p_{y}=u_{1}^{\prime}\left(c_{y}^{1}\right)$ for $y=1,2,3$. Now the expressions (4) immediately determine the state-contingent stock prices.

$$
\begin{aligned}
& q^{1}=(28.864,16.487,15.220)^{\top} \\
& q^{2}=(27.346,15.620,14.419)^{\top} .
\end{aligned}
$$

For asset markets to be dynamically complete we need three assets in the economy. Suppose that in addition to the two stocks there is also a consol. The linear equation (4) for the consol allows us to trivially calculate the price vector $q^{c}$ of the consol,

$$
q^{c}=(29.432,16.812,15.519)^{\top} .
$$

Finally, we can solve the linear system of equations (6) to determine agents' equilibrium portfolios. This system is independent of the prices of the two stocks and the consol. Agents' portfolio holdings depend solely on the stocks' dividend vectors, the consol payoffs, and agents' consumption vectors. Equations (6) for agent 1 are

$$
\Theta^{11} \cdot d^{1}+\Theta^{12} \cdot d^{2}+\Theta^{1 c} \cdot 1_{3}=0.8 \cdot\left(d^{1}+d^{2}\right)-0.579 \cdot 1_{3} .
$$


Observe that the agent's portfolio holdings are simply given by the coefficients of her linear sharing rule. The slope coefficient on the aggregate endowment gives us the agent's portfolio position in each stock. Agent 1's sharing rule has slope 0.8 and she holds $\Theta^{11}=\Theta^{12}=0.8$ units of both stocks. The constant term of an agent's sharing rule determines her holding of the consol. Agent 1's sharing rule has a constant term of -0.579 and so holds $\Theta^{1 c}=-0.579$ units of the consol, that is, she has a short position of 0.579 units of the consol. Thus, we trivially obtain the following equilibrium portfolios.

$$
\begin{aligned}
& \Theta^{1}=\left(\begin{array}{ll}
0.8,0.8, & -0.579
\end{array}\right)^{\top} \\
& \Theta^{2}=\left(\begin{array}{ll}
0.2,0.2, & 0.579
\end{array}\right)^{\top} .
\end{aligned}
$$

Now consider an economy with a one-period bond instead of the consol. Markets are again dynamically complete and so the equilibrium consumption allocations and stock prices do not change. Equations (5) determine the state-contingent prices of the one-period bond. The bond price vector $q^{b}$ is

$$
q^{b}=(1.472,0.841,0.776)^{\top} .
$$

Equations (6) again determine agents' equilibrium portfolios. But these equations are somewhat different for an economy with a one-period bond than for an economy with a consol. The bond is short-lived and therefore its price vector enters the equations. For agent 1 these equations appear as follows.

$$
\Theta^{11} \cdot d^{1}+\Theta^{12} \cdot d^{2}+\Theta^{1 b} \cdot\left(1_{3}-q^{b}\right)=0.8 \cdot\left(d^{1}+d^{2}\right)-0.579 \cdot 1_{3} .
$$

We can no longer just read off the agent's portfolio holdings. The appearance of the nonconstant bond price vector $q^{b}$ prohibits us from doing so. Solving this linear system of equations yields the following equilibrium portfolios.

$$
\begin{aligned}
& \Theta^{1}=(0.560,0.450,-0.371)^{\top} \\
& \Theta^{2}=(0.440,0.550,0.371)^{\top} .
\end{aligned}
$$

The agents' portfolios do not exhibit two-fund monetary separation. The less risk-averse agent 1 holds considerably less of the two stocks while the more risk-averse agent 2 holds considerably more of the two stocks than in the economy with a consol.

We point out that a generalized notion of two-fund separation continues to hold. Note that we can rewrite the left-hand side of equations (8) as follows.

$$
\begin{aligned}
0.560 \cdot d^{1}+0.450 \cdot d^{2}- & 0.371 \cdot\left(1_{3}-q^{b}\right) \\
& =0.8 \cdot\left(d^{1}+d^{2}\right)+\left(-0.240 \cdot d^{1}-0.350 \cdot d^{2}-0.371 \cdot\left(1_{3}-q^{b}\right)\right),
\end{aligned}
$$

where

$$
\frac{1}{-0.579} \cdot\left(-0.240 \cdot d^{1}-0.350 \cdot d^{2}-0.371 \cdot\left(1_{3}-q^{b}\right)\right)=1_{3} .
$$

That is, a mutual fund consisting of $\frac{240}{579}$ units of the first stock, $\frac{350}{579}$ units of the second stock, and $\frac{371}{579}$ units of the one-period bond, synthesizes the consol. So we can view 
the agents' portfolios as consisting of two mutual funds, one holding (risky) stocks in equal units and the other holding various amounts of stocks and the one-period bond. This second mutual fund synthesizes the consol. But this generalized form of twofund separation is not what most people have in mind when they talk about two-fund separation-see Canner et al. (1997) or Elton and Gruber (2000). People usually think of two-fund monetary separation in the sense of Cass and Stiglitz (1970).

This simple example reveals the main difference between the role of a consol and that of a one-period bond in agents' budget equations. A consol is an infinitely-lived security and so the agents do not trade the consol after time zero. As a result the price of the consol does not appear in the budget equations (7). We can trivially solve these equations by simply comparing the coefficients in the linear sharing rule to the portfolio weights on all assets. Two-fund separation holds. Contrary to the consol the oneperiod bond is a short-lived security. While all agents have a constant position of the one-period bond in each period, they must reestablish this position every period. Thus the price of the bond appears in the budget equation (8). And this fact results in a different solution for agents' portfolio holdings. In particular, two-fund separation does not hold.

We can relate our results to those of Merton (1973). If the price and thus the interest rate of the one-period bond did not vary, then two-fund separation would hold. But as in Merton's model, the fluctuation of the short-term interest rate destroys two-fund separation. As we have also seen, a generalized form of two-fund separation holds in the economy with the one-period bond. The mutual fund synthesizing the consol perfectly hedges any movements in the short-term bond price. The role of the other assets in this mutual fund is thus comparable to the purpose of the asset whose returns are perfectly negatively correlated with the interest rate in Merton's model that ensures the threefund theorem. So, our results under the assumption of equi-cautious HARA utilities bear some similarity to Merton's under the assumption of log-normal returns. But in our model agents do not trade after period zero unlike in the continuous-time model, where they trade continuously.

We continue our intuitive discussion in Section 5.3 after the formal statements of our results on two-fund separation. In order to establish those results we next develop some technical background. A reader who is not interested in technical details may want to skip the next section and instead continue with Section 5 .

\section{EQUiLIBRIUM: EXISTENCE AND PROPERTIES}

This section lays the groundwork for our analysis of two-fund separation in Section 5. We first summarize the assumptions underlying the system of equations (1)-(6), which is the foundation for all the analysis in this paper. Next we use this system to describe some properties of equilibria in our model that are relevant for the analysis of two-fund separation. And finally we derive linear sharing rules from equations (1) for economies with equi-cautious HARA utility functions. 


\subsection{Assumptions}

Judd et al. (2003) need a few assumptions in addition to those mentioned in the model description to derive their no-trade result and their characterization of equilibria by equations (1)-(6). Our analysis prohibits some of these assumptions, so we need to make some adjustments. We now introduce and discuss our modifications.

Judd et al. (2003) impose an Inada condition $\left(\lim _{x \rightarrow 0} u_{h}^{\prime}(x)=\infty\right)$ to ensure that the solutions to equations (1)-(3) yield positive consumption allocations. We cannot make that assumption since some of the classical utility functions that yield two-fund separation (e.g., quadratic utility) do not satisfy such an Inada condition. Instead we allow for the possibility of negative consumption. Those of our utility functions that do not satisfy an Inada condition have the property $\lim _{x \rightarrow-\infty} u_{h}^{\prime}(x)=\infty$. Therefore, equations (1)-(3) have a solution that is bounded below and thus an interior point of a consumption set (interval) that allows for sufficiently negative consumption. In addition, we need to ensure that consumption remains non-satiated since we want to avoid free disposal of income. We do not state (tedious) assumptions on fundamentals and refer to Magill and Quinzii (2000, Proposition 3), who show for quadratic utilities how to restrict parameters to ensure positive and non-satiated consumption. In summary, for an appropriately chosen consumption set, equations (1)-(3) are necessary and sufficient for a consumption allocation of an efficient financial market equilibrium. (Ideally we think of specifications of the model that result in strictly positive consumption allocations.)

For our analysis of agents' portfolios we adopt the following key assumption from Judd et al. (2003).

[A1] All elements of the transition matrix $\Pi$ are positive:

$$
\Pi \in\left\{A \in \mathbb{R}^{S \times S}: A_{y s}>0 \quad \forall y, s \in \mathscr{Y}, \quad \sum_{s=1}^{S} A_{y s}=1 \quad \forall y \in \mathscr{Y}\right\} .
$$

This assumption ensures the buy-and-hold nature of equilibrium portfolios. If the transition matrix contains zero elements then a continuum of portfolios supports an efficient equilibrium allocation. For our application of the parametric transversality theorem (see Section A of the Appendix) using Assumption [A1] it is useful to define an open set that is diffeomorphic to the set of admissible transition matrices,

$$
\Delta_{++}^{S \times(S-1)} \equiv\left\{A_{y s}, y \in \mathscr{Y}, s \in\{1, \ldots, S-1\}: A_{y s}>0, \quad \sum_{s=1}^{S-1} A_{y s}<1 \quad \forall y \in \mathscr{Y}\right\} .
$$

We identify transition matrices with elements in $\Delta_{++}^{S \times(S-1)}$. Remark 1 below explains why it is sensible to have genericity statements with respect to transition probabilities.

We also make the following assumption about the dividend and payoff vectors of the assets.

[A2] $\operatorname{Rank}[d]=S$. 
Judd et al. (2003) impose a full rank condition only on the dividends of long-lived assets and then prove their results for generic payoffs of the short-lived assets. We cannot follow this approach because we want to examine a particular short-lived asset, namely a riskless one-period bond. Assumption [A2] is needed to ensure that an efficient financial market equilibrium exists.

The following assumption is not crucial but simplifies our genericity arguments.

[A3] All agents have a positive initial position of the first long-lived asset.

We define the open set $\Delta_{++}^{H-1} \equiv\left\{x \in \mathbb{R}_{++}^{H-1}: \sum_{i=1}^{H-1} x_{i}<1\right\}$. The assumption requires $\left(\theta_{-1}^{h 1}\right)_{h \geq 2}=\left(\theta_{-1}^{21}, \theta_{-1}^{31}, \ldots, \theta_{-1}^{H 1}\right) \in \Delta_{++}^{H-1}$. We make statements for generic individual holdings in $\Delta_{++}^{H-1}$ below.

\subsection{Some equilibrium properties}

Equilibria in economies without aggregate risk, that is, in economies with a stateindependent social endowment, have such a simple structure that any further analysis is unnecessary. For completeness we summarize the equilibrium properties of such economies.

PROPOSITION 1 (Equilibrium without aggregate risk). Suppose the aggregate endowment is constant: $e_{y}=\hat{e}$ for all $y \in \mathscr{Y}$.

(1) Consumption allocations and asset prices are the same in every efficient financial market equilibrium. Allocations are state-independent. Consumption allocations, asset prices, and portfolios are independent of agents' utility functions.

(2) If [A1] and [A2] hold, then the equilibrium is unique. Each agent holds constant shares of all long-lived assets in unit net supply and trades neither short-lived assets nor long-lived assets in zero net supply.

Proposition 1 completely characterizes efficient financial market equilibria in economies without aggregate uncertainty. Portfolios satisfy what one could call a "one-fund" property. Such a simple equilibrium makes any further analysis of two-fund separation superfluous. Our main results in this paper are for economies with a riskless asset. For such economies the full-rank assumption [A2] immediately implies that the social endowment in the economy is not constant. That is, there exist $y_{1}, y_{2} \in \mathscr{Y}$ such that $e\left(y_{1}\right) \neq e\left(y_{2}\right)$.

Judd et al. (2003) prove existence of efficient financial market equilibria for generic dividends of the short-lived assets. We cannot use this existence result since the analysis of two-fund separation requires particular payoff structures. Therefore we prove an alternative existence result that suits our analysis.

Proposition 2 (Equilibrium with aggregate risk). Consider an economy $\mathscr{E}$ satisfying assumption [A2].

(i) If all $S$ assets are long-lived, then the economy $\mathscr{E}$ has an efficient financial market equilibrium. 
(ii) Suppose also [A1] and [A3] hold. If there are S-1 long-lived assets in unit net supply and a one-period bond, then $\mathscr{E}$ has an efficient equilibrium for generic subsets $\mathscr{T} \subset$ $\Delta_{++}^{H-1}$ of initial holdings of the first asset and $\mathscr{P} \subset \Delta_{++}^{S \times(S-1)}$ of transition matrices.

We also show the following lemma in Section B of the Appendix.

LEMMA 1. In an efficient financial market equilibrium of the economy $\mathscr{E}$ the price of a one-period bond, $q^{b}$, has the following characteristics.

(i) The price $q^{b}$ is constant if and only if the aggregate endowment is constant. In that case the bond price equals the discount factor: $q_{y}^{b}=\beta$ for all $y \in \mathscr{Y}$.

(ii) Suppose $S \geq 3$ and [A1], [A2], and [A3] hold. For generic subsets $\mathscr{T} \subset \Delta_{++}^{H-1}$ of initial holdings of the first asset and $\mathscr{P} \subset \Delta_{++}^{S \times(S-1)}$ of transition matrices the price of a oneperiod bond is not a linear function of the aggregate endowment. That is, there do not exist numbers $a, f \in \mathbb{R}$ such that $q_{y}^{b}=a \cdot e_{y}+f$ for all $y \in \mathscr{Y}$.

At first it may be surprising that part (ii) of the lemma only holds for a generic set of transition probabilities. We explain why this condition is needed in Remark 1 below.

\subsection{Linear sharing rules}

Linear sharing rules for consumption are the foundation of two-fund separation on financial markets. Using standard terminology we say that equilibrium consumption adheres to a linear sharing rule if it satisfies

$$
c_{y}^{h}=m^{h} e_{y}+b^{h} \quad \forall h \in \mathscr{H}, y \in \mathscr{Y}
$$

for real numbers $m^{h}, b^{h}$ for all agents $h \in \mathscr{H}$. Obviously, in equilibrium we have $\sum_{h=1}^{H} m^{h}=1$ and $\sum_{h=1}^{H} b^{h}=0$. Our results in this paper show that we have to carefully distinguish between linear sharing rules with nonzero intercepts and those for which $b^{h}=0$ for all $h \in \mathscr{H}$.

Recall that the absolute risk tolerance of agent $h$ 's utility function $u_{h}: X \rightarrow \mathbb{R}$ is defined as $T_{h}(c)=-u_{h}^{\prime}(c) / u_{h}^{\prime \prime}(c)$. Of particular interest for linear sharing rules are utility functions with linear absolute risk tolerance, that is, $T_{h}(c)=a^{h}+g^{h} c$, for real numbers $g^{h}$ and $a^{h}$. These utility functions make up the well-known family of HARA (hyperbolic absolute risk aversion) utilities (see Gollier 2001, Hens and Pilgrim 2002). If all agents have HARA utilities and all their linear absolute risk tolerances have identical slopes, that is, $g^{h} \equiv g$ for all $h \in \mathscr{H}$ for some slope $g$, then the agents are said to have equicautious HARA utilities.

Utility functions exhibiting linear absolute risk tolerance with constant but nonzero slope for all agents have the form

$$
u_{h}(c)= \begin{cases}K\left(A^{h}+\frac{c}{\gamma}\right)^{1-\gamma} & \text { for } \gamma \neq 0,1, \quad c \in\left\{c \in \mathbb{R}: A^{h}+c / \gamma>0\right\} \\ \ln \left(A^{h}+c\right) & \text { for } \gamma=1, \quad c \in\left\{c \in \mathbb{R}: A^{h}+c>0\right\}\end{cases}
$$


with $K=\operatorname{sign}((1-\gamma) / \gamma)$ to ensure that $u$ is strictly increasing and strictly concave (on some appropriate consumption set). The absolute risk tolerance for these utility functions is $T_{h}(c)=A^{h}+c / \gamma$. If $\gamma>0$ and $A^{h}=0$ for all $h \in \mathscr{H}$ then we have the special case of utility functions with identical constant relative risk aversion (CRRA). If $\gamma=-1$ then all agents have quadratic utility functions.

The limit case for utility functions of the type [EC] as $\gamma \rightarrow \infty$ is the set of utility functions with constant absolute risk aversion (CARA). We write

$$
u_{h}(c)=-\frac{1}{a^{h}} e^{-a^{h} c}
$$

with constant absolute risk tolerance of $T_{h}(c)=1 / a^{h} \equiv \tau^{h}$.

We need the following lemma for our analysis. It follows from the classical results on Pareto-efficient sharing rules by Wilson (1968) and Amershi and Stoeckenius (1983). Rubinstein (1974) establishes the connection between consumption sharing rules and asset market equilibrium. See Gollier (2001) for a textbook treatment of a static equilibrium problem.

LEMMA 2. If all agents have equi-cautious HARA utilities, then the consumption allocation of each agent in an efficient equilibrium satisfies a linear sharing rule.

We calculate the sharing rules directly by solving the Negishi equations (1) for given weights $\lambda^{h}$ for all $h \in \mathscr{H}$. For utility functions of type [EC], equations (1) become

$$
\left(A^{1}+\frac{c^{1}}{\gamma}\right)^{-\gamma}-\lambda^{h}\left(A^{h}+\frac{c^{h}}{\gamma}\right)^{-\gamma}=0, \quad h \in \mathscr{H}, y \in \mathscr{Y},
$$

where we include the trivial equation for agent 1 with weight $\lambda^{1}=1$ to simplify the subsequent expressions. Some algebra leads to the linear sharing rule

$$
c_{y}^{h}=e_{y} \cdot\left(\frac{\left(\lambda^{h}\right)^{\frac{1}{\gamma}}}{\sum_{i \in \mathscr{H}}\left(\lambda^{i}\right)^{\frac{1}{\gamma}}}\right)+\gamma\left(-A^{h}+\frac{\left(\lambda^{h}\right)^{\frac{1}{\gamma}}}{\sum_{i \in \mathscr{H}}\left(\lambda^{i}\right)^{\frac{1}{\gamma}}} \sum_{i \in \mathscr{H}} A^{i}\right) .
$$

Note that for the special case of CRRA utility functions $\left(A^{h}=0\right.$ for all $h \in \mathscr{H}$ ), the sharing rule has zero intercept. For CARA utility functions the linear sharing rules are given by

$$
c_{y}^{h}=e_{y} \cdot \frac{\tau^{h}}{\sum_{i \in \mathscr{H}} \tau^{i}}+\left(\tau^{h} \ln \left(\lambda^{h}\right)-\frac{\tau^{h}}{\sum_{i \in \mathscr{H}} \tau^{i}} \sum_{i \in \mathscr{H}} \tau^{i} \ln \left(\lambda^{i}\right)\right) .
$$

Recall that in our illustrative example in the previous section agents had coefficients of absolute risk aversion of $a^{1}=1$ and $a^{2}=4$ and thus risk tolerances of $\tau^{1}=1$ and $\tau^{2}=0.25$, respectively. This observation explains why we encountered linear sharing rules with the respective slopes of 0.8 and 0.2 in the example. 
REMARK 1 . The necessity of genericity with respect to transition probabilities in Lemma 1 is now apparent. If transition probabilities are i.i.d. and all agents have HARA utility with $\gamma=1$ (but possibly $A^{h} \neq 0$ ), then the linear sharing rule leads to the bond price being a linear function of the endowment for any set of dividends and initial portfolios. If $c_{y}^{h}=m^{h} e_{y}+b^{h}$ for all $y \in \mathscr{Y}$ then

$$
q_{y}=\beta\left(\sum_{s \in \mathscr{Y}} \Pi_{y s} \frac{1}{e_{s}+\sum_{h \in \mathscr{H}} A^{h}}\right)\left(e_{y}+\sum_{h \in \mathscr{H}} A^{h}\right) .
$$

Making genericity arguments with respect to transition probabilities saves us from having to distinguish this case from the general case. We cannot allow for the popular perturbations of utility functions as, for example, in Cass and Citanna (1998) and Citanna et al. (2006), since we want to examine two-fund separation for specific classical families of utility functions.

Two-fund separation in models with a one-period bond (see Section 5.2) depends crucially on whether the intercept of the sharing rules is zero. We prove the following lemma in Section B of the Appendix.

LEMMA 3. Suppose all agents have equi-cautious HARA utility functions of the type [CARA] or the type [EC] with $\sum_{h \in \mathscr{H}} A^{h} \neq 0$ and [A3] holds. Then, for a generic set $\mathscr{T} \subset \Delta_{++}^{H-1}$ of initial holdings of the first asset, each agent's sharing rule is linear with nonzero intercept; that is, $b^{h} \neq 0$ for all $h \in \mathscr{H}$.

For standard equi-cautious CRRA utility functions with $A^{h}=0$ for all $h \in \mathscr{H}$ we have $b^{h}=0, \forall h \in \mathscr{H}$.

\section{TWO-FUND SEPARATION: CONSOL VS. ONE-PERIOD BOND}

This section formalizes the intuition that we gained from our illustrative example in Section 3. A trivial proof shows that in an economy with a consol, portfolios exhibit twofund separation. We then prove that this property generically fails to hold in economies with a one-period bond. A discussion tying together our illustrative example and mathematical proofs concludes our analysis.

\subsection{Economies with a consol}

In this subsection we assume that there are no short-lived assets; that is, $J^{l}=S$. Then equation (6) immediately yields that the consumption vector of every agent $h$ is a linear combination of the asset dividends (or payoffs),

$$
c^{h}=\left(d^{1}, \ldots, d^{S}\right) \Theta^{h} .
$$

Under the assumptions that all assets are infinitely lived and that there is a safe asset, we recover the classical two-fund monetary separation result for static demands of Cass and Stiglitz (1970) in our dynamic equilibrium context. 
THEOREM 1 (Two-Fund Separation Theorem). Suppose the economy $\mathscr{E}$ has $S$ infinitely lived assets with linearly independent payoff vectors and satisfies Assumptions [A1] and [A2]. The first $S-1$ assets are in unit net supply and asset $S$ is a consol in zero net supply. If the agents have equi-cautious HARA utilities then in an efficient equilibrium their portfolios exhibit two-fund monetary separation.

Proof. Proposition 2 ensures that an efficient equilibrium exists. Lemma 2 implies that sharing rules are linear and $c_{y}^{h}=m^{h} e_{y}+b^{h} \forall h \in \mathscr{H}, y \in \mathscr{Y}$. Under the assumptions of the theorem, equation (9) has the unique solution $\Theta^{h S}=b^{h}$ and $\Theta^{h j}=m^{h} \forall j=$ $1, \ldots, S-1$.

We can easily extend Theorem 1 to economies with $J<S$ long-lived assets. Markets are dynamically complete with fewer assets than states and so portfolios exhibit twofund separation for $J<S$ when a consol is present.

Kang (2003, Chapter 4) observes that the results of Judd et al. (2003) can be generalized to economies with time-varying positive transition probabilities. In addition, he notices that the results also hold for finite-horizon economies with only long-lived assets. We can use these observations to extend the result of Theorem 1 to economies with a finite time horizon or time-varying (positive) transition matrices. Either change to our model affects the Negishi weights $\lambda^{h}, h \in \mathscr{H}$, and sharing rules $m^{h}, b^{h}, h \in \mathscr{H}$, but two-fund monetary separation continues to hold.

\subsection{One-period riskless bond}

We now assume that the riskless asset is not a consol but instead a one-period bond. In addition the economy has $S-1$ infinitely lived assets in unit net supply. In such an economy two-fund monetary separation generically fails even when sharing rules are linear with nonzero intercepts.

THEOREM 2. Consider an economy $\mathscr{E}$ that satisfies the following conditions.

(i) There are $J=S \geq 3$ assets.

(ii) There are S - 1 infinitely lived securities in unit net supply. The last asset is a oneperiod riskless bond.

(iii) Assumptions [A1]-[A3] hold.

(iv) All agents have equi-cautious HARA utility functions of the type [CARA] or the type [EC] with $\sum_{h \in \mathscr{H}} A^{h} \neq 0$.

Then there are generic subsets $\mathscr{T} \subset \Delta_{++}^{H-1}$ of initial portfolios of the first asset and $\mathscr{P} \subset \Delta_{++}^{S \times(S-1)}$ of transition matrices such that each agent's equilibrium portfolio does not exhibit two-fund monetary separation. 
PROOF. All agents' consumption allocations follow a linear sharing rule. Now suppose that equilibrium portfolios exhibit two-fund monetary separation, so agent $h$ holds a portion $\vartheta^{h} \equiv \Theta^{h j}$ of all infinitely lived assets $j=1, \ldots, S-1$, and $\Theta^{h S}$ of the one-period bond. Then equation (6) implies that the portfolio shares satisfy

$$
m^{h} \cdot e+b^{h} 1_{S}=\vartheta^{h} \cdot e+\Theta^{h S}\left(1_{S}-q^{S}\right) \quad \text { for all } h \in \mathscr{H},
$$

where $q^{S}$ denotes the bond price and $1_{S}$ the vector consisting solely of ones. If $b^{h}=0$ for all $h \in \mathscr{H}$ then $\Theta^{h S}=0$ and $m^{h}=\vartheta^{h}$ is a solution to this equation. Thus, two-fund monetary separation holds. But Lemma 3 states that under conditions (iii) and (iv) we have $b^{h} \neq 0$ for all $h \in \mathscr{H}$ for a generic set of initial portfolio holdings.

Now suppose $b^{h} \neq 0$ for all $h$. Then any solution to equation (10) must have $\Theta^{h S} \neq 0$. Thus we can rewrite the equation as

$$
q^{S}=\frac{\vartheta^{h}-m^{h}}{\Theta^{h S}} \cdot e+\frac{\Theta^{h S}-b^{h}}{\Theta^{h S}} \cdot 1_{S}
$$

But now the price of the one-period bond is a linear function of the aggregate endowment. Lemma 1, part (ii), states that for a generic set of initial portfolios and transition matrices there are no (endogenous) coefficients $a, f \in \mathbb{R}$ such that $q^{S}=a \cdot e+f$. Hence, equation (10) generically does not have a solution. The intersection of generic sets is generic. The statement of the theorem now follows.

\subsection{Discussion}

Recall that our illustrative example already provides us with much intuition for the main results of this paper. Now that we have seen the proofs of our two theorems we can continue the discussion from Section 3. Equation (10) in the proof of Theorem 2 is very instructive in providing intuition for the lack of two-fund monetary separation when the bond is short-lived. Recall that for an economy with a consol the corresponding equation would be

$$
m^{h} \cdot e+b^{h} 1_{S}=\vartheta^{h} \cdot e+\Theta^{h S} 1_{S} \quad \text { for all } h \in \mathscr{H} .
$$

So the only difference that the short-lived bond introduces into the portfolio equation is that the bond position $\Theta^{h S}$ is multiplied by the coupon payment minus the price instead of being multiplied only by the coupon payment. The economic reason for this difference is that the agent does not trade the consol after time zero but must reestablish the position in the short-lived bond in every period. This change has no impact on the portfolio weights if agents' sharing rules have zero intercept and so the riskless security is not traded. But if sharing rules have nonzero intercept, then the bond price affects the portfolio weights. The appearance of the bond price still does not destroy two-fund monetary separation if this price is a linear function of the social endowment. But if that relationship does not hold, then the fluctuations of the bond price lead to a change of the portfolio weights that implement equilibrium consumption.

In summary, fluctuations in the equilibrium interest rates (bond prices) of the shortterm bond lead to the breakdown of two-fund monetary separation. These fluctuations 
expose an agent holding a nonzero bond position in equilibrium to reinvestment risk because he must rebuild that position in every period. This reinvestment risk affects agents' bond and thus stock portfolios and leads to a change of the equilibrium portfolio weights. In contrast, in an economy with a consol, the agent establishes a position in the consol at time zero once and for all. Fluctuations in the price of the consol therefore do not affect the agent, just as he is unaffected by stock price fluctuations. The agent does not have to reinvest the proceeds from an expiring security at fluctuating prices and so does not face reinvestment risk. This fact allows him to hold a portfolio exhibiting two-fund monetary separation. In our dynamic model only the consol is a riskless asset.

The fact that interest rate variability has significant economic consequences in a dynamic equilibrium model has also been noted by Magill and Quinzii (2000). They examine an infinite-horizon CAPM economy with stochastic endowments and observe that with fewer assets than states an Arrow-Debreu allocation can be achieved only if a constant consumption stream can be spanned by the payoff matrix. But such a spanning condition may not hold if the interest rate fluctuates in equilibrium. As a consequence markets will be incomplete.

\section{Asset ALLOCATION PUZZLE}

In a paper that received a lot of attention in the finance literature, Canner et al. (1997) document recommendations from different investment advisers who all encourage conservative investors to hold a higher ratio of bonds to stocks than aggressive investors. ${ }^{1}$ They point out that this financial planning advice violates the two-fund monetary separation theorem and call this observation the "asset allocation puzzle." Similarly, Bossaerts et al. (forthcoming) state that the separation result cannot be reconciled with casual empirical observations and conclude that "many tests of asset pricing models address only the pricing predictions-but these pricing predictions rest on portfolio choice predictions which seem obviously wrong."

Both critiques assume that the classical notion of two-fund monetary separation is applicable to the dynamic world of modern financial markets. This supposition is a far-reaching generalization of the two-fund separation paradigm beyond the classical results (Cass and Stiglitz 1970, Merton 1973, and many others), which make strong assumptions on utility functions or return distributions. Moreover, both critiques clearly assume the existence of a riskless asset in actual financial markets. Canner et al. (1997) explicitly regard cash as the "safe" asset.

In light of the results in this paper, it should come as no surprise that observed investors' portfolios do not satisfy two-fund separation. Cash is a safe investment only in the very short term (see also, for example, Campbell and Viceira 2002). Because

\footnotetext{
${ }^{1}$ Canner et al. consider portfolios consisting of stocks, bonds, and cash, with cash being treated as the risk-free asset. They document that investment advisors recommend conservative (and even moderately risk averse) investors to hold a significant fraction of their wealth—beyond what liquidity needs would require-in cash assets. Advisors treat bonds as being somewhat risky relative to cash, so that the riskyasset portfolio consists of both stocks and bonds. The fact that the recommended ratio of these assets depends on the investor's risk aversion violates portfolio separation.
} 
investors must continually reinvest cash in the future at unknown and fluctuating interest rates, cash is not a safe asset for the long term. Instead cash positions expose investors to reinvestment risk. Therefore, we should not consider cash as a riskless asset in dynamic financial markets. Arguably investors do not have access to a truly safe asset. On modern financial markets, investors can certainly trade a huge number of financial assets including many finite-maturity bonds. But consols (with the exception of some perpetual bonds issued by the British Treasury in the 19th century) are not available for trade. And although (inflation-indexed) bonds with many different maturities do exist, investors cannot trade such bonds with a maturity matching just any desired (very long) investment horizon.

In summary, the critiques of Canner et al. (1997) and Bossaerts et al. (forthcoming) are based on the incorrect assumption that investors have access to a safe asset. Their criticism of two-fund monetary separation is, therefore, not justified. For further discussion of the asset allocation puzzle, see Brennan and Xia (2000).

Our results naturally lead us to question whether modern financial markets may enable investors to synthesize a consol through a variety of other assets, thereby leading to a generalized form of two-fund separation. Judd et al. (2006a) study this question by examining families of bonds with variable but finite maturity structures. They argue that a finite number of bonds can span a consol for some non-generic transition matrices and dividend structures. In such situations all agents hold the same fund of risky stocks. Their computational exercises show that this result does not hold in general but that such portfolios can be approximately optimal in general if bonds with a sufficiently rich maturity structure are available for trade.

\section{APPENDIX}

\section{A. Parametric Systems of EQUations}

We state the theorem on a parametric system of equations that we use in the genericity proofs below.

THEOREM 3 (Parametric Systems of Equations). Let $\Omega \subset \mathbb{R}^{k}, X \subset \mathbb{R}^{n}$ be open sets and let $h: \Omega \times X \rightarrow \mathbb{R}^{m}$ be a smooth function. If $n<m$ and for all $(\bar{\omega}, \bar{x}) \in \Omega \times X$ such that $h(\bar{\omega}, \bar{x})=0$ we have $\operatorname{rank}\left[D_{\omega, x} h(\bar{\omega}, \bar{x})\right]=m$, then there exists a set $\Omega^{*} \subset \Omega$ with $\Omega-\Omega^{*}$ a set of Lebesgue measure zero, such that $\{x \in X: h(\omega, x)=0\}=\emptyset$ for all $\omega \in \Omega^{*}$.

For a detailed discussion of this theorem see Magill and Quinzii (1996b, Paragraph 11; 1996a). This theorem is a specialized version of the parametric transversality theorem (see Guillemin and Pollack 1974, Chapter 2, Paragraph 3, and Mas-Colell 1985, Chapter 8). Billingsley (1986, Section 12) provides a detailed exposition on the $k$ dimensional Lebesgue measure in Euclidean space. For an exposition of sets of measure zero see Guillemin and Pollack (1974, Chapter 1, Paragraph 7). A set is said to have full measure if its complement is a set of Lebesgue measure zero. An open set of full Lebesgue measure is called generic. 


\section{B. PROOFS}

This section contains all proofs that are omitted in the main body of the paper.

Proof of Proposition 1. Market-clearing and collinearity of marginal utilities imply that in an efficient equilibrium all agents have state-independent consumption allocations. Define $\hat{c}^{h} \equiv \bar{c}_{y}^{h}$ for all $y \in \mathscr{Y}$. Equations (2) imply that the agents' consumption allocations are

$$
\hat{c}^{h}=\frac{\left(\left[I_{S}-\beta \Pi\right]^{-1}\right)_{y_{0}} \cdot \omega^{h}}{\sum_{s \in \mathscr{Y}}\left(\left[I_{S}-\beta \Pi\right]^{-1}\right)_{y_{0} s}}
$$

for all $h \in \mathscr{H}$. The resulting asset prices are $q^{j}=\left[I_{S}-\beta \Pi\right]^{-1} \beta \Pi d^{j}, j \in L$ for infinitely lived assets and $q^{j}=\beta \Pi d^{j}, j \in O$ for one-period assets. If the matrix $d$ has full column rank then the solution to equations (6) is unique and gives the agents' holdings of infinitely-lived assets $j \in L$ in unit net supply,

$$
\Theta^{h j}=\frac{\hat{c}^{h}}{\hat{e}}=\frac{1}{\hat{e}} \frac{\left(\left[I_{S}-\beta \Pi\right]^{-1}\right)_{y_{0}} \cdot \omega^{h}}{\sum_{s \in \mathscr{Y}}\left(\left[I_{S}-\beta \Pi\right]^{-1}\right)_{y_{0} s}} .
$$

(If the matrix $d$ does not have full column rank then this solution is only one in a continuum of optimal portfolios.) The agents do not trade any of the other assets (including infinitely-lived assets in zero net supply). Note that all expressions in this proof are independent of the agents' utility functions.

Proof of Proposition 2. The existence result of Mas-Colell and Zame (1991) implies that there exist equilibrium state-contingent consumption values $c_{y}^{h}, h \in \mathscr{H}, y \in \mathscr{Y}$, that solve the system of equations (1)-(3). The critical remaining issue for the existence of an efficient financial market equilibrium is now whether the matrix $D$ has full rank. In that case equations (6) yield the agents' equilibrium portfolios. (Actually, a careful reading of Judd et al. 2003 shows that we also need the matrix $\left(d^{1}+q^{1}, \ldots, d^{J^{l}}+q^{J^{l}}, d^{J^{l}+1}, \ldots, d^{S}\right)$ to have full rank. But that condition is equivalent to $D$ having full rank.)

If all assets are long-lived then $D=d$ and so $D$ has full rank. We now show that for economies with a one-period riskless bond the matrix $D$ generically has full rank. If $D$ does not have full rank then the following set of equations must have a solution.

$$
\begin{aligned}
u_{1}^{\prime}\left(c_{y}^{1}\right)-\lambda^{h} u_{h}^{\prime}\left(c_{y}^{h}\right)=0, & & h=2, \ldots, H, y \in \mathscr{Y} \\
\left(\left[I_{S}-\beta \Pi\right]^{-1}\left(p \otimes\left(c^{h}-\sum_{j \in L} \theta_{-1}^{h j} d^{j}\right)\right)\right)_{y_{0}}=0, & & h=2, \ldots, H \\
\sum_{h=1}^{H} c_{y}^{h}-e_{y}=0, & & y \in \mathscr{Y} \\
q_{y}^{S} p_{y}-\beta \Pi_{y \cdot} p=0, & & y \in \mathscr{Y} \\
\sum_{j \in L} d^{j}(y) a_{j}+\left(1-q^{S}(y)\right)=0, & & y \in \mathscr{Y} .
\end{aligned}
$$


We denote the system of equations (11)-(15) by $F\left(\left(c^{h}\right)_{h \in \mathscr{H}},\left(\lambda^{h}\right)_{h \geq 2}, q^{S}, a ;\left(\theta_{-1}^{h 1}\right)_{h \geq 2}, \Pi_{1}\right)$ $=0$. The expression $F_{(i)}=0$ denotes equations $(i)$. We now show that this system has no solutions for generic sets of individual holdings of the first asset and transition probabilities.

The system (11)-(15) has $H S+(H-1)+S+(S-1)$ endogenous unknowns $c^{h}, h \in \mathscr{H}$, $\lambda^{h}, h=2, \ldots, H, q^{S}$, and $a_{j}, j=1, \ldots, S-1$, in $(H-1) S+(H-1)+S+S+S$ equations. In addition, the function $F$ depends on the $(H-1)+S$ exogenous parameters $\left(\theta_{-1}^{h 1}\right)_{h \geq 2} \in$ $\Delta_{++}^{H-1}$ and $\Pi_{.1}$ where $\Pi^{-S} \in \Delta_{++}^{S \times(S-1)}$ denotes the first $S-1$ columns of $\Pi$. Assumption [A2] allows us to assume without loss of generality that $e_{1} \neq e_{S}$.

We now prove that the Jacobian of $F$ taken with respect to $c^{h}, q^{S}, \theta_{-1}^{h 1}$, and $\Pi_{.1}$ has full row $\operatorname{rank}(H-1) S+(H-1)+S+S+S$. Denote by $\Lambda_{S}(x) \in \mathbb{R}^{S \times S}$ the diagonal matrix whose diagonal elements are the elements of the vector $x \in \mathbb{R}^{S}$. We denote the derivative of the budget constraints (12) with respect to the agent's initial holding in the first infinitely lived asset, $-\left(\left[I_{S}-\beta \Pi\right]^{-1}\left(p \otimes d^{1}\right)\right)_{y_{0}}$, by $\eta^{1}$. Note that $\eta^{1}<0$. In order to keep the display tractable, we show the Jacobian of $F$ for the special case of $H=3$ and write $D_{\Pi_{1 .}} F_{(14)}$ for $-\beta \Lambda\left(\left(p_{1}-p_{S}\right) \cdot 1_{S}\right)$.

\begin{tabular}{|c|c|c|c|c|c|c|c|}
\hline & $c^{1}$ & $c^{2}$ & $c^{3}$ & $q^{S}$ & $\theta_{-1}^{21}$ & $\theta_{-1}^{31}$ & $\Pi_{1}$ \\
\hline$F_{(11)_{h=2}}$ & $\Lambda_{S}\left(u_{1}^{\prime \prime}\left(c^{1}\right)\right)$ & $\Lambda_{S}\left(-\lambda^{2} u_{2}^{\prime \prime}\left(c^{2}\right)\right)$ & 0 & 0 & 0 & 0 & 0 \\
\hline$F_{(11)_{h=3}}$ & $\Lambda_{S}\left(u_{1}^{\prime \prime}\left(c^{1}\right)\right)$ & 0 & $\Lambda_{S}\left(-\lambda^{3} u_{3}^{\prime \prime}\left(c^{3}\right)\right)$ & 0 & 0 & 0 & 0 \\
\hline$F_{(12)_{h=2}}$ & & & 0 & 0 & $\eta^{1}$ & 0 & \\
\hline$F_{(12)_{h=3}}$ & & 0 & & 0 & 0 & $\eta^{1}$ & \\
\hline$F_{(13)}$ & $I_{S}$ & $I_{S}$ & $I_{S}$ & 0 & 0 & 0 & 0 \\
\hline$F_{(14)}$ & & 0 & 0 & & 0 & 0 & $D_{\Pi_{.1}} F_{(14)}$ \\
\hline$F_{(15)}$ & 0 & 0 & 0 & $-I_{S}$ & 0 & 0 & 0 \\
\hline
\end{tabular}

The variables above the matrix indicate the variables with respect to which derivatives have been taken in the column underneath. The numbers to the right and below the matrix indicate the number of rows and columns, respectively. The terms to the left indicate the equations. Missing entries are not needed for the proof.

We now perform column operations to obtain zero matrices in the first set of columns of the Jacobian. The sets of columns for $c^{h}, h \in \mathscr{H}$, of the Jacobian then appear as follows.

\begin{tabular}{|c|c|c|c|}
\hline \multirow{5}{*}{$\begin{array}{l}F_{(11)_{h=2}} \\
F_{(11)_{h=3}} \\
F_{(12)_{h=2}} \\
F_{(12)_{h=3}}\end{array}$} & $c^{1}$ & $c^{2}$ & $c^{3}$ \\
\hline & 0 & $\Lambda_{S}\left(-\lambda^{2} u_{2}^{\prime \prime}\left(c^{2}\right)\right)$ & 0 \\
\hline & 0 & 0 & $\Lambda_{S}\left(-\lambda^{3} u_{3}^{\prime \prime}\left(c^{3}\right)\right)$ \\
\hline & & & 0 \\
\hline & & 0 & \\
\hline$F_{(13)}$ & $I_{S}+\Lambda\left(\frac{u_{1}^{\prime \prime}\left(c^{1}\right)}{\lambda^{2} u_{2}^{\prime \prime}\left(c^{2}\right)}\right)+\Lambda\left(\frac{u_{1}^{\prime \prime}\left(c^{1}\right)}{\lambda^{3} u_{3}^{\prime \prime}\left(c^{3}\right)}\right)$ & $I_{S}$ & $I_{S}$ \\
\hline$F_{(14)}$ & & 0 & 0 \\
\hline$F_{(15)}$ & 0 & 0 & 0 \\
\hline
\end{tabular}


The transformed matrix has submatrices of the following ranks.

\begin{tabular}{|c|c|c|c|c|c|c|c|}
\hline \multirow[b]{2}{*}{$F(11)_{h=2}$} & $c^{1}$ & $c^{2}$ & $c^{3}$ & $q^{S}$ & $\theta_{-1}^{21}$ & $\theta_{-1}^{31}$ & $\Pi_{.1}$ \\
\hline & 0 & $S$ & 0 & 0 & 0 & 0 & 0 \\
\hline$F_{(11)_{h=3}}$ & 0 & 0 & $S$ & 0 & 0 & 0 & 0 \\
\hline$F_{(12)_{h=2}}$ & & & 0 & 0 & 1 & 0 & \\
\hline$F_{(12)_{h=3}}$ & & 0 & & 0 & 0 & 1 & \\
\hline$F_{(13)}$ & $S$ & $S$ & $S$ & 0 & 0 & 0 & 0 \\
\hline$F_{(14)}$ & & 0 & 0 & & 0 & 0 & $S$ \\
\hline$F_{(15)}$ & 0 & 0 & 0 & $S$ & 0 & 0 & 0 \\
\hline
\end{tabular}

The term $D_{\Pi_{1}} F_{(14)}=-\beta \Lambda\left(\left(p_{1}-p_{S}\right) \cdot 1_{S}\right)$ has rank $S$ since $p_{1} \neq p_{S}$ because $e_{1} \neq e_{S}$.

This matrix has full row $\operatorname{rank}(H-1) S+(H-1)+3 S$ which exceeds the number of endogenous variables by 1 . The function $F$ is defined on open sets with $c^{h} \in \operatorname{int}(X)$ for all $h \in \mathscr{H}, \lambda^{h} \in \mathbb{R}_{++}^{S}$ for $h \geq 2, a \in \mathbb{R}^{S-1}, q^{S} \in \mathbb{R}_{++}^{S},\left(\theta_{-1}^{h 1}\right)_{h \geq 2} \in \Delta_{++}^{H-1}$, and $\Pi^{-S} \in \Delta_{++}^{S \times(S-1)}$. Hence $F$ satisfies the hypotheses of the theorem on parametric systems of equations, Theorem 3. We conclude that there exist subsets $\mathscr{T} \subset \Delta_{++}^{h-1}$ and $\mathscr{P} \subset \Delta_{++}^{S \times(S-1)}$ of full Lebesgue measure such that the solution set of the system (11)-(15) is empty. The sets $\mathscr{T}$ and $\mathscr{P}$ are open. The solutions to (11)-(15) change smoothly with the exogenous parameters. A small variation in initial portfolios and probabilities does not lead to a solvable system if there is no solution for the original parameters.

We conclude that the matrix $D$ has full rank $S$ and so an equilibrium exists for initial holdings $\left(\theta_{-1}^{h 1}\right)_{h \geq 2} \in \mathscr{T}$ of the first asset and transition matrices such that $\Pi^{-S} \in \mathscr{P}$.

Proof of Lemma 1. Part (i). The price of the one-period bond is $q_{y}^{b}=\beta \Pi_{y} \cdot u_{1}^{\prime}(c) / u_{1}^{\prime}\left(c_{y}\right)$, where $u_{1}^{\prime}(c)$ denotes the column vector of utilities $u_{1}^{\prime}\left(c_{y}\right), y \in \mathscr{Y}$. If the social endowment $e$ is not constant, every agent has nonconstant consumption. Choose $y_{1} \in$ $\arg \min \left\{c_{y}^{1}: y \in \mathscr{Y}\right\}$ such that $\Pi_{y_{1} s}>0$ for some $s \notin \arg \min \left\{c_{y}^{1}: y \in \mathscr{Y}\right\}$. Similarly, choose $y_{2} \in \arg \max \left\{c_{y}^{1}: y \in \mathscr{Y}\right\}$ such that $\Pi_{y_{2} s}>0$ for some $s \notin \arg \max \left\{c_{y}^{1}: y \in \mathscr{Y}\right\}$. Obviously, $y_{1} \neq y_{2}$. Then $\Pi_{y_{1}} . u_{1}^{\prime}(c)<u_{1}^{\prime}\left(c_{y_{1}}\right)$ and $\Pi_{y_{2}} . u_{1}^{\prime}(c)>u_{1}^{\prime}\left(c_{y_{2}}\right)$ and so $q_{y_{2}}^{b}>\beta>q_{y_{1}}^{b}$. If there is no aggregate risk in the economy, then the bond price equation immediately yields $q^{b}=\beta$.

Part (ii). The price of the one-period bond in state $y \in \mathscr{Y}$ satisfies $q_{y} p_{y}=\beta \Pi_{y} . p$. If in equilibrium the price is a linear function of the social endowment $e$, then the following set of equations must have a solution.

$$
\begin{aligned}
u_{1}^{\prime}\left(c_{y}^{1}\right)-\lambda^{h} u_{h}^{\prime}\left(c_{y}^{h}\right)=0, & h=2, \ldots, H, y \in \mathscr{Y} \\
\left(\left[I_{S}-\beta \Pi\right]^{-1}\left(p \otimes\left(c^{h}-\sum_{j \in L} \theta_{-1}^{h j} d^{j}\right)\right)\right)_{y_{0}}=0, & h=2, \ldots, H \\
\sum_{h=1}^{H} c_{y}^{h}-e_{y}=0, & y \in \mathscr{Y} \\
\left(a e_{y}+f\right) p_{y}-\beta \Pi_{y} \cdot p=0, & y \in \mathscr{Y} .
\end{aligned}
$$


We denote the system of equations (16)-(19) by $F\left(\left(c^{h}\right)_{h \in \mathscr{H}},\left(\lambda^{h}\right)_{h \geq 2}, a, f ;\left(\theta_{-1}^{h 1}\right)_{h \geq 2}, \Pi_{1}\right)=$ 0 . The expression $F_{(i)}=0$ denotes equations $(i)$. The system has $H S+(H-1)+2$ endogenous unknowns $c^{h}, h \in \mathscr{H}, \lambda^{h}, h=2, \ldots, H, a$, and $f$ and $(H-1) S+(H-1)+S+S$ equations. (Note that the coefficients $a$ and $f$ of the linear price function are endogenous variables.) In addition, $F$ depends on the $(H-1)+S$ exogenous parameters $\theta_{-1}^{h 1}, h=$ $2, \ldots, H$, and $\Pi_{.1}$. The aggregate endowment is not constant and so we can assume without loss of generality that $p_{1} \neq p_{S}$.

The Jacobian of $F$ taken with respect to $c^{h}, \theta_{-1}^{h 1}$, and $\Pi_{.1}$ is identical to the respective columns of the corresponding submatrix in the proof of Proposition 2. After performing the same column operations as in that proof we obtain a transformed matrix with submatrices of the following ranks.

\begin{tabular}{c|c|c|c|c|c|c|c} 
& \multicolumn{1}{c}{$c^{1}$} & $c^{2}$ & $c^{3}$ & $\theta_{-1}^{21}$ & $\theta_{-1}^{31}$ & $\Pi_{\cdot 1}$ \\
$F_{(16)_{h=2}}$ & 0 & $S$ & 0 & 0 & 0 & 0 & $S$ \\
$F_{(16)_{h=3}}$ & 0 & 0 & $S$ & 0 & 0 & 0 & $S$ \\
$F_{(17)_{h=2}}$ & & & 0 & 1 & 0 & & 1 \\
$F_{(17)_{h=3}}$ & & 0 & & 0 & 1 & & 1 \\
$F_{(18)}$ & $S$ & $S$ & $S$ & 0 & 0 & 0 & $S$ \\
$F_{(19)}$ & & 0 & 0 & 0 & 0 & $S$ & $S$ \\
\cline { 2 - 8 } & \multicolumn{2}{c|}{$S$} & $S$ & $S$ & 1 & 1 & \multicolumn{1}{c}{$S$}
\end{tabular}

This matrix has full row $\operatorname{rank}(H-1) S+(H-1)+S+S$ which exceeds the number of endogenous variables by $S-2 \geq 1$. The function $F$ is defined on open sets with $c^{h} \in \operatorname{int}(X)$ for all $h \in \mathscr{H}, \lambda^{h} \in \mathbb{R}_{++}^{S}$ for $h \geq 2, a, f \in \mathbb{R},\left(\theta_{-1}^{h 1}\right)_{h \geq 2} \in \Delta_{++}^{H-1}$ and $\Pi^{-S} \in \Delta_{++}^{S \times(S-1)}$. Hence, $F$ satisfies the hypotheses of Theorem 3 and the proof proceeds like that of Proposition 2.

Proof of Lemma 3. We first consider an economy where all agents have equi-cautious HARA utility functions of the type [EC]. Then if $b^{h}=0$ for some agent $h$ in equilibrium the following equations must hold.

$$
\begin{aligned}
& u_{1}^{\prime}\left(c_{y}^{1}\right)-\lambda^{h} u_{h}^{\prime}\left(c_{y}^{h}\right)=0, \quad h=2, \ldots, H, y \in \mathscr{Y} \\
& \left(\left[I_{S}-\beta \Pi\right]^{-1}\left(p \otimes\left(c^{h}-\sum_{j \in L} \theta_{-1}^{h j} d^{j}\right)\right)\right)_{y_{0}}=0, \quad h=2, \ldots, H \\
& \sum_{h=1}^{H} c_{y}^{h}-e_{y}=0, \quad y \in \mathscr{Y} \\
& \left(-A^{\bar{h}}+\frac{\left(\lambda^{\bar{h}}\right)^{\frac{1}{\gamma}}}{\sum_{i \in \mathscr{H}}\left(\lambda^{i}\right)^{\frac{1}{\gamma}}} \sum_{i \in \mathscr{H}} A^{i}\right)=0, \quad \text { for one } \bar{h} \in \mathscr{H} \text {. }
\end{aligned}
$$

We denote the system of equations (20)-(23) by $F\left(\left(c^{h}\right)_{h \in \mathscr{H}},\left(\lambda^{h}\right)_{h \geq 2} ;\left(\theta_{-1}^{h 1}\right)_{h \geq 2}\right)=0$. The system has $H S+(H-1)$ endogenous unknowns $c^{h}, h \in \mathscr{H}$ and $\lambda^{h}, h=2, \ldots, H$, and $(H-1) S+(H-1)+S+1$ equations. In addition, the function $F$ depends on the $H-1$ exogenous parameters $\theta_{-1}^{h 1}, h=2, \ldots, H$. We show that the Jacobian of $F$ taken with respect to $c^{h}, \lambda^{h}$, and $\theta_{-1}^{h 1}$ has full row $\operatorname{rank}(H-1) S+(H-1)+S+1$. 
For $\bar{h} \geq 2$ denote the derivative in equation (23) with respect to $\lambda^{\bar{h}}$ by

$$
\eta_{\bar{h}}^{2}=\frac{\frac{1}{\gamma}\left(\lambda^{\bar{h}}\right)^{\frac{1}{\gamma}-1} \cdot\left(\sum_{i=1}^{H}\left(\lambda^{i}\right)^{\frac{1}{\gamma}}-\left(\lambda^{\bar{h}}\right)^{\frac{1}{\gamma}}\right)}{\left(\sum_{i=1}^{H}\left(\lambda^{i}\right)^{\frac{1}{\gamma}}\right)^{2}} \sum_{i=1}^{H} A^{i} .
$$

For $\bar{h}=1$ we cannot take the derivative in (20) with respect to $\lambda^{1}$, since it does not appear (it is normalized to one). Instead we differentiate with respect to $\lambda^{2}$ and obtain

$$
\eta_{1}^{2}=-\frac{\frac{1}{\gamma}\left(\lambda^{2}\right)^{\frac{1}{\gamma}-1}}{\left(\sum_{i=1}^{H}\left(\lambda^{i}\right)^{\frac{1}{\gamma}}\right)^{2}} \sum_{i=1}^{H} A^{i} .
$$

Note that under the condition from the lemma, $\sum_{i \in \mathscr{H}} A^{i} \neq 0$, we have $\eta_{\bar{h}}^{2} \neq 0$. For the

\begin{tabular}{|c|c|c|c|c|c|c|}
\hline & $c^{1}$ & $c^{2}$ & $c^{3}$ & $\theta_{-1}^{21}$ & $\theta_{-1}^{31}$ & \multirow[t]{2}{*}{$\lambda^{h}$} \\
\hline$F_{(20)_{h=2}}$ & $\Lambda_{S}\left(u_{1}^{\prime \prime}\left(c^{1}\right)\right)$ & $\Lambda_{S}\left(-\lambda^{2} u_{2}^{\prime \prime}\left(c^{2}\right)\right)$ & 0 & 0 & 0 & \\
\hline$F_{(20)_{h=3}}$ & $\Lambda_{S}\left(u_{1}^{\prime \prime}\left(c^{1}\right)\right)$ & 0 & $\Lambda_{S}\left(-\lambda^{3} u_{3}^{\prime \prime}\left(c^{3}\right)\right)$ & 0 & 0 & \\
\hline$F_{(21)_{h=2}}$ & & & 0 & $\eta^{1}$ & 0 & 0 \\
\hline$F_{(21)_{h=3}}$ & & 0 & & 0 & $\eta^{1}$ & 0 \\
\hline$F_{(22)}$ & $I_{S}$ & $I_{S}$ & $I_{S}$ & 0 & 0 & 0 \\
\hline$F_{(23)}$ & 0 & 0 & 0 & 0 & 0 & $\eta_{\bar{h}}^{2}$ \\
\hline & $S$ & $S$ & $S$ & 1 & 1 & $S$ \\
\hline
\end{tabular}

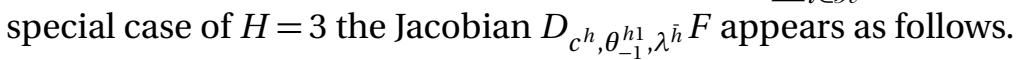

After the same column operations as in the proof of Proposition 2 we obtain the follow-

\begin{tabular}{|c|c|c|c|c|c|c|}
\hline \multirow{7}{*}{$\begin{array}{c}F_{(20)_{h=2}} \\
F_{(20)_{h=3}} \\
F_{(21)_{h=2}} \\
F_{(21)_{h=3}} \\
F_{(22)} \\
F_{(23)}\end{array}$} & $c^{1}$ & $c^{2}$ & $c^{3}$ & $\theta_{-1}^{21}$ & $\theta_{-1}^{31}$ & $\lambda^{\bar{h}}$ \\
\hline & 0 & $S$ & 0 & 0 & 0 & \\
\hline & 0 & 0 & $S$ & 0 & 0 & \\
\hline & & & 0 & 1 & 0 & 0 \\
\hline & & 0 & & 0 & 1 & 0 \\
\hline & $S$ & $S$ & $S$ & 0 & 0 & 0 \\
\hline & 0 & 0 & 0 & 0 & 0 & 1 \\
\hline
\end{tabular}
ing ranks for the various submatrices of the transformed matrix.

This matrix has full row rank $H S+(H-1)+1$ which exceeds the number of endogenous variables by 1 . The function $F$ is defined on open sets with $c^{h} \in \operatorname{int}(X)$ for all $h \in \mathscr{H}$, $\lambda^{h} \in \mathbb{R}_{++}^{S}$ for $h \geq 2$, and $\left(\theta_{-1}^{h 1}\right)_{h \geq 2} \in \Delta_{++}^{H-1}$. Hence, $F$ satisfies the hypotheses of Theorem 3 and the proof proceeds like that of Proposition 2. We can perform the proof for each agent and then take the intersection of generic sets which in turn yields a generic set for which no agent has a linear sharing rule with zero intercept. 
In the proof for CARA utilities we must replace equation (23) with the equation

$$
\tau^{\bar{h}} \ln \left(\lambda^{\bar{h}}\right)-\frac{\tau^{\bar{h}}}{\sum_{i \in \mathscr{H}} \tau^{i}} \sum_{i \in \mathscr{H}} \tau^{i} \ln \left(\lambda^{i}\right)=0
$$

for some agent $\bar{h} \in \mathscr{H}$. The proof is now identical to the one for [EC] type utilities.

\section{REFERENCES}

Amershi, Amin H. and Jan H. W. Stoeckenius (1983), "The theory of syndicates and linear sharing rules.” Econometrica, 51, 1407-1416. [148]

Billingsley, Patrick (1986), Probability and Measure, second edition. Wiley, New York. [153]

Bossaerts, Peter, Charles Plott, and William R. Zame (forthcoming), "Prices and portfolio choices in financial markets: Theory, econometrics, experiments." Econometrica. [152, 153]

Bossaerts, Peter and William R. Zame (2006), "Asset trading volume in infinite-horizon economies with dynamically complete markets and heterogeneous agents: Comment." Finance Research Letters, 3, 96-101. [139]

Brennan, Michael J. and Yihong Xia (2000), "Stochastic interest rates and the bond-stock mix.” European Finance Review, 4, 197-210. [153]

Campbell, John Y. and Luis M. Viceira (2002), Strategic Asset Allocation: Portfolio Choice for Long-Term Investors. Oxford University Press, Oxford. [152]

Canner, Niko, N. Gregory Mankiw, and David N. Weil (1997), "An asset allocation puzzle.” American Economic Review, 87, 181-191. [136, 144, 152, 153]

Cass, David and Alessandro Citanna (1998), "Pareto improving financial innovation in incomplete markets.” Economic Theory, 11, 467-494. [149]

Cass, David and Joseph E. Stiglitz (1970), “The structure of investor preferences and asset returns, and separability in portfolio allocation: A contribution to the pure theory of mutual funds." Journal of Economic Theory, 2, 122-160. [135, 136, 137, 141, 144, 149, 152]

Citanna, Alessandro, Herakles M. Polemarchakis, and Mario Tirelli (2006), "The taxation of trades in assets." Journal of Economic Theory, 126, 299-313. [149]

Elton, Edwin J. and Martin J. Gruber (2000), “The rationality of asset allocation recommendations." Journal of Financial and Quantitative Analysis, 35, 27-41. [136, 144]

Gollier, Christian (2001), The Economics of Risk and Time. MIT Press, Cambridge, Massachusetts. [137, 147, 148] 
Guillemin, Victor and Alan Pollack (1974), Differential Topology. Prentice-Hall, Englewood Cliffs, New Jersey. [153]

Hens, Thorsten and Beate Pilgrim (2002), General Equilibrium Foundations of Finance. Kluwer, Boston, Massachusetts. [147]

Huang, Chi-fu and Robert H. Litzenberger (1988), Foundations for Financial Economics. North-Holland, New York. [137, 141]

Ingersoll, Jonathan E. (1987), Theory of Financial Decision Making. Rowman and Littlefield, Totowa, New Jersey. [137, 141]

Judd, Kenneth L., Felix Kubler, and Karl Schmedders (2003), "Asset trading volume with dynamically complete markets and heterogeneous agents." Journal of Finance, 58, 22032217. [136, 139, 140, 145, 146, 150, 154]

Judd, Kenneth L., Felix Kubler, and Karl Schmedders (2006a), "Bond portfolios and twofund separation in the Lucas asset-pricing model.” Discussion Paper 1427, Center for Mathematical Studies in Economics and Management Sciences, Northwestern University. [153]

Judd, Kenneth L., Felix Kubler, and Karl Schmedders (2006b), "Reply to 'Asset trading volume in infinite-horizon economies with dynamically complete markets and heterogeneous agents: Comment'." Finance Research Letters, 3, 102-105. [139]

Kang, Jong-Gu (2003), A multi-period complete market economy. Ph.D. thesis, University of Essex. [150]

Lucas, Robert E. (1978), "Asset prices in an exchange economy." Econometrica, 46, 14291445. [136, 138]

Magill, Michael and Martine Quinzii (1996a). Unpublished Chapter 8 of Volume 2 of “Theory of Incomplete Markets". [153]

Magill, Michael and Martine Quinzii (1996b), Theory of Incomplete Markets, Volume 1. MIT Press, Cambridge, Massachusetts. [153]

Magill, Michael and Martine Quinzii (2000), "Infinite horizon CAPM equilibrium.” Economic Theory, 15, 103-138. [145, 152]

Markowitz, Harry M. (1959), Portfolio Selection: Efficient Diversification of Investments. Wiley, New York. [136]

Mas-Colell, Andreu (1985), The Theory of General Economic Equilibrium: A Differentiable Approach. Cambridge University Press, Cambridge, UK. [153]

Mas-Colell, Andreu and William R. Zame (1991), "Equilibrium theory in infinite dimensional spaces." In Handbook of Mathematical Economics, Volume 4 (Werner Hildenbrand and Hugo Sonnenschein, eds.), 1835-1898, North-Holland, Amsterdam. [154] 
Merton, Robert C. (1971), "Optimum consumption and portfolio rules in a continuoustime model.” Journal of Economic Theory, 3, 373-413. [137]

Merton, Robert C. (1973), "An intertemporal capital asset pricing model." Econometrica, 41, 867-887. [135, 136, 137, 141, 144, 152]

Merton, Robert C. (1990), Continuous-Time Finance. Blackwell, Malden, Massachusetts. [137]

Negishi, Takashi (1960), "Welfare economics and existence of an equilibrium for a competitive economy.” Metroeconomica, 12, 92-97. [140]

Ross, Stephen A. (1978), "Mutual fund separation in financial theory-the separating distributions.” Journal of Economic Theory, 17, 254-286. [137]

Rubinstein, Mark (1974), "An aggregation theorem for securities markets." Journal of Financial Economics, 1, 225-244. [137, 148]

Russell, Thomas (1980), "Portfolio separation: The analytic case." Economics Letters, 6, 59-66. [137]

Tobin, James (1958), "Liquidity preference as behavior towards risk." Review of Economic Studies, 25, 65-86. [136]

Wilson, Robert B. (1968), “The theory of syndicates.” Econometrica, 36, 119-132. [148]

Submitted 2007-1-20. Final version accepted 2007-5-2. Available online 2007-5-2. 